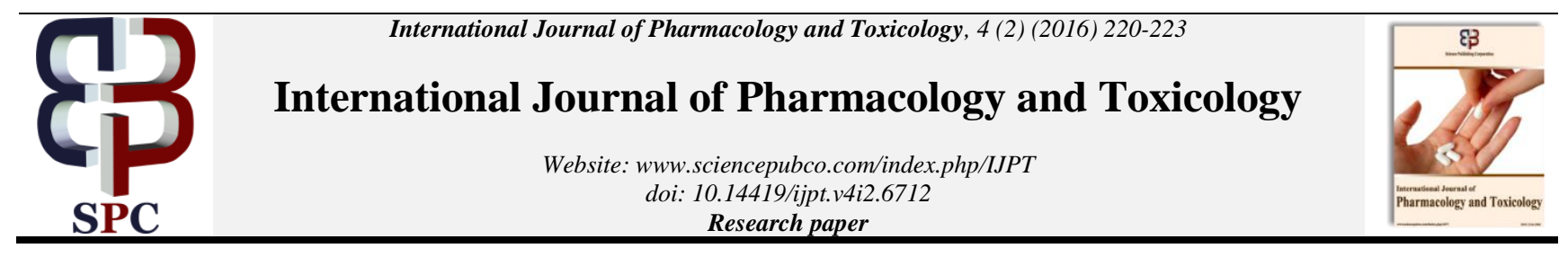

\title{
Study on management of various poisoning cases at a tertiary care teaching hospital
}

\author{
Sriram.S ${ }^{1}$, Nissy Anu Wilson ${ }^{2}$ \\ ${ }^{1}$ Department of Clinical Pharmacy, College of Pharmacy, SRIPMS Coimbatore \\ ${ }^{2}$ Pharm D V yr, College of Pharmacy,SRIPMS, Coimbatore \\ *Corresponding author E-mail: visitram@yahoo.com
}

\begin{abstract}
Aim/Objective: The main objective of the study is to assess the management of various poisoning cases and to know the role a clinical pharmacist can play in management and prognosis of poisoning cases.

Method: A Retrospective study was carried out for a period of three months to know the various poisoning cases admitted in the intensive care units of a tertiary care teaching hospital. All the data regarding the patient and the management of the case were recorded in a pre-designed patient profile form and were analyzed. The study also focuses on preparing a nomogram for the management of various types of poisoning in the study site. It is also planned to study the co-relation between education status and their implications in prognosis of the poisoning cases.

Result: A total of 22 patients of various poisoning cases were studied, out of which 13 intentional (69.23\%) and 9 unintentional (40.90\%) poisonings were reported. It was seen that adults between the age of 21-30yrs were more prone to suicidal poisoning.

Conclusion: The majority of poisoning cases were with the use of drugs for suicidal purpose, in young age group and women. Activities including preventive measures, professional education and public education and also clinical pharmacist intervention/involvement in management of poisoning cases in the hospital by providing poison information is the need of the hour.
\end{abstract}

Keywords: Adverse Effect; Nomogram; and Poison.

\section{Introduction}

Poison can be defined as substance that cause harmful effects when administered either accident/intentionally to a living organism. Poisonings constitute a major public health problem worldwide and they are one of the major causes of patient admissions to emergency departments and intensive care units, especially in developing countries. According to World Health Organization, (WHO) poisoning occurs when people drink, eat, breathe, inject, or touch enough of a hazardous substance (poison) to cause illness or death.

Poisoning pattern in a region depends on availability of poisons, socio economic status of the population, religious- cultural influences and also occupation prevalent in the region. WHO conservatively estimated that though developing countries account for only $15 \%$ of the worldwide use of pesticides, about $50 \%$ of pesticide poisonings occur in these countries, especially through misuse of chemicals (Thapa et al.2008). Organophosphates were most common agent used for intentional attempt of incidence followed by Phosphides (Deepak Pokhrel et al.2008). About 35000-50000 people die every year from snake bite which is common cause of morbidity and mortality in India.most of the childhood poisoning were accidental in nature. The mean hospital stay was not more than two and in very few condition it last for a week mostly seen in case with the use of organophosphorus (Buddhi Prasad 2005, Kiran N,et al 2008). Organophosphorus compounds used widely in developing countries like India.Many cases occurs due to unawareness of proper usage so proper guidelines are required and precautions are necessary to handle the poisoning conditions (Eddleston 2000).

Considering the cost and outcomes of the poison cases reported to the hospitals, it is found necessary to establish a Poison Information Centre (PIC) which should be networked with other poison information centre's in India and with other countries, by which identifying the poisons and managing the cases will become more efficient. Reducing deaths due to poisoning requires improved medical management of acute poisoning (Dash et al.2005).

\section{Objective}

The main objective of the study is to assess the management of various poisoning cases and to know the role a clinical pharmacist can play in management and prognosis of poisoning cases.

\section{Methods}

A Retrospective study was carried out for a period of three months to know the various poisoning cases admitted in the intensive care units of a tertiary care teaching hospital. All the data regarding the patient and the management of the case were recorded in a predesigned patient profile form and were analyzed. The study also focuses on preparing a nomogram for the management of various types of poisoning in the study site. An attempt is made to educate the patient and the patient attenders regarding the adverse effects the poison could produce on various organs resulting in increase in cost of therapy. It is also planned to study the co-relation between 
education status and their implications in prognosis of the poisoning cases.

\section{Results and findings}

In the present study of 22 patients of various poisoning cases were studied, out of which 13 intentional and 9 unintentional poisonings were reported. Intentional $(69.23 \%)$ poisoning was more than that of unintentional cases $(40.90 \%)$. From these, $63.63 \%$ were females and $6.36 \%$ were males (Table 1). Suicidal attempts were more common in females than males. It was seen that adults between the ages of 21-30yrs were more prone to suicidal poisoning (Bharati et al.2001, Ghazi Khansari 1995). Risk and predisposing factors are found to be stress and strain in day to day life and also the HIV+ve condition. Children between the ages of 1-10 were more susceptible to accidental poisoning. Accidental ingestion of cow dung powder was seen in $9.09 \%$ children lead to liver damage, severe cardiac events such as bradycardia, hypotention in organophosphorous poisoning and ARF in venom poisoning cases. Commonly used antidotes are atropine and pralidoxime chloride (Dart 2003). Most of the patients presented with poisoning were $69.23 \%$ from the rural background and $30.32 \%$ from the urban dwelling. Serum cholinesterase levels were monitored in OPC poisoning (Batra et al.2003). Duration of treatment varies according to severity from 2 days to 12 days and also because patients are not willing to stay longer in emergency department due to the cost of poisoning treatment (Khadka et al.2005).

Table 1: Poison and Antidotes

\begin{tabular}{ll}
\hline Poison & Management \\
\hline Organophosphate(OP) & $\begin{array}{l}\text { Pralidoxime(2PAM),atropine\& benzodiaze- } \\
\text { pines(diazepam) }\end{array}$ \\
Yellow cow dung pow- & Activated charcoal \\
der & Activated charcoal \\
Paraquat(dipyridylium) & Flumazenil \\
Benzodiazepine & Activated charcoal \\
Nifedipine & Anti-venom \\
Snake bite & Atropine\&Isoprenaline \\
Oleander seed &
\end{tabular}

Table 2: Poison and Affected Organs

\begin{tabular}{ll}
\hline Poison & Affected Organ \\
\hline Organophosphate(OP) & Liver damage \\
Yellow cow dung powder & Liver damage \\
Paraquat(dipyridylium) & Lungs \& kidney damage \\
Benzodiazepine & Liver damage \\
Nifedipine & Heart malfunction \\
Snake bite & Renal and neural damage \\
Oleander seed & Kidney damage \\
\hline
\end{tabular}

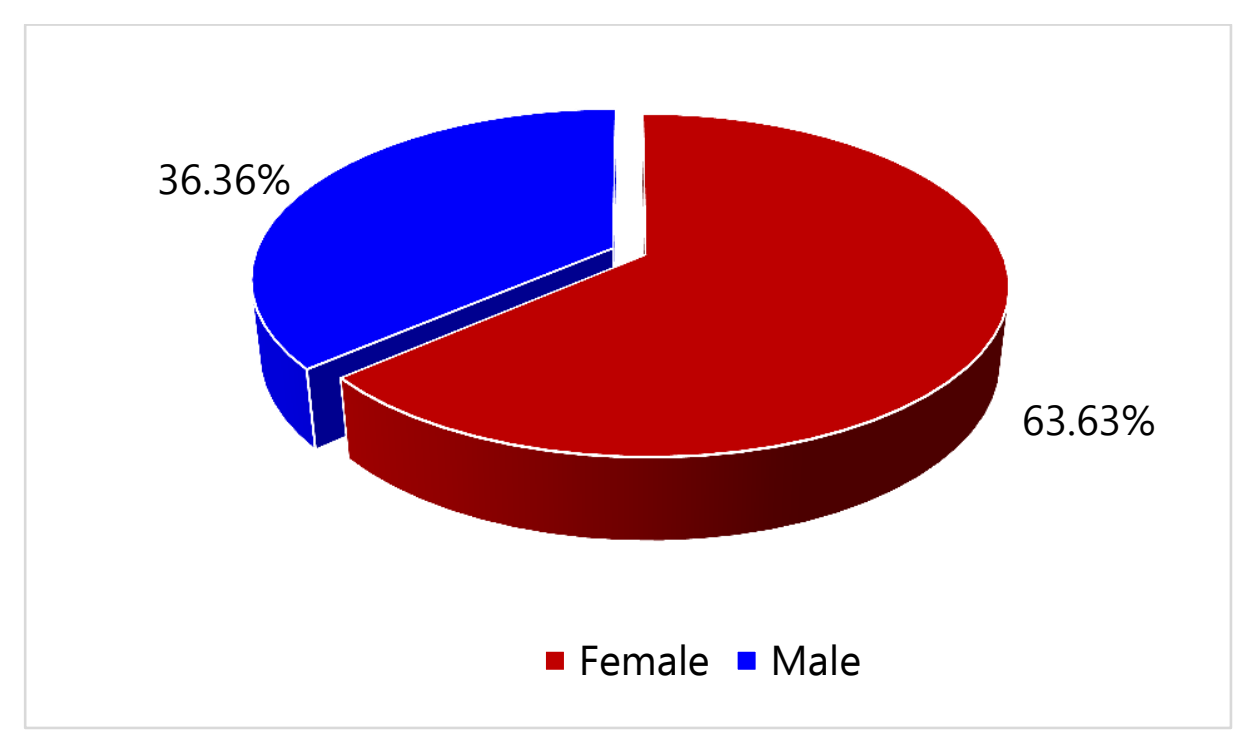

Fig. 1: Socio Demographic Details of Patients- Gender.

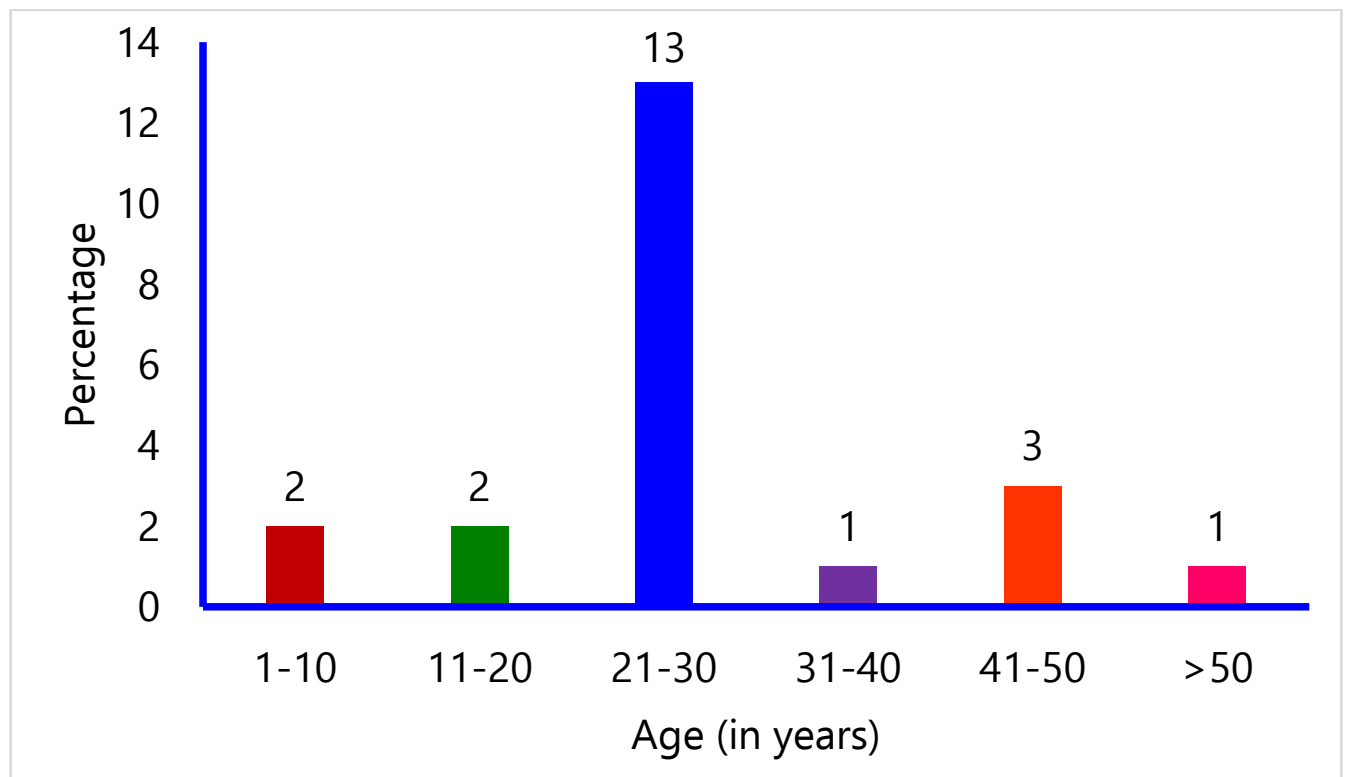

Fig. 2: Socio Demographic Details of Patients-Age. 


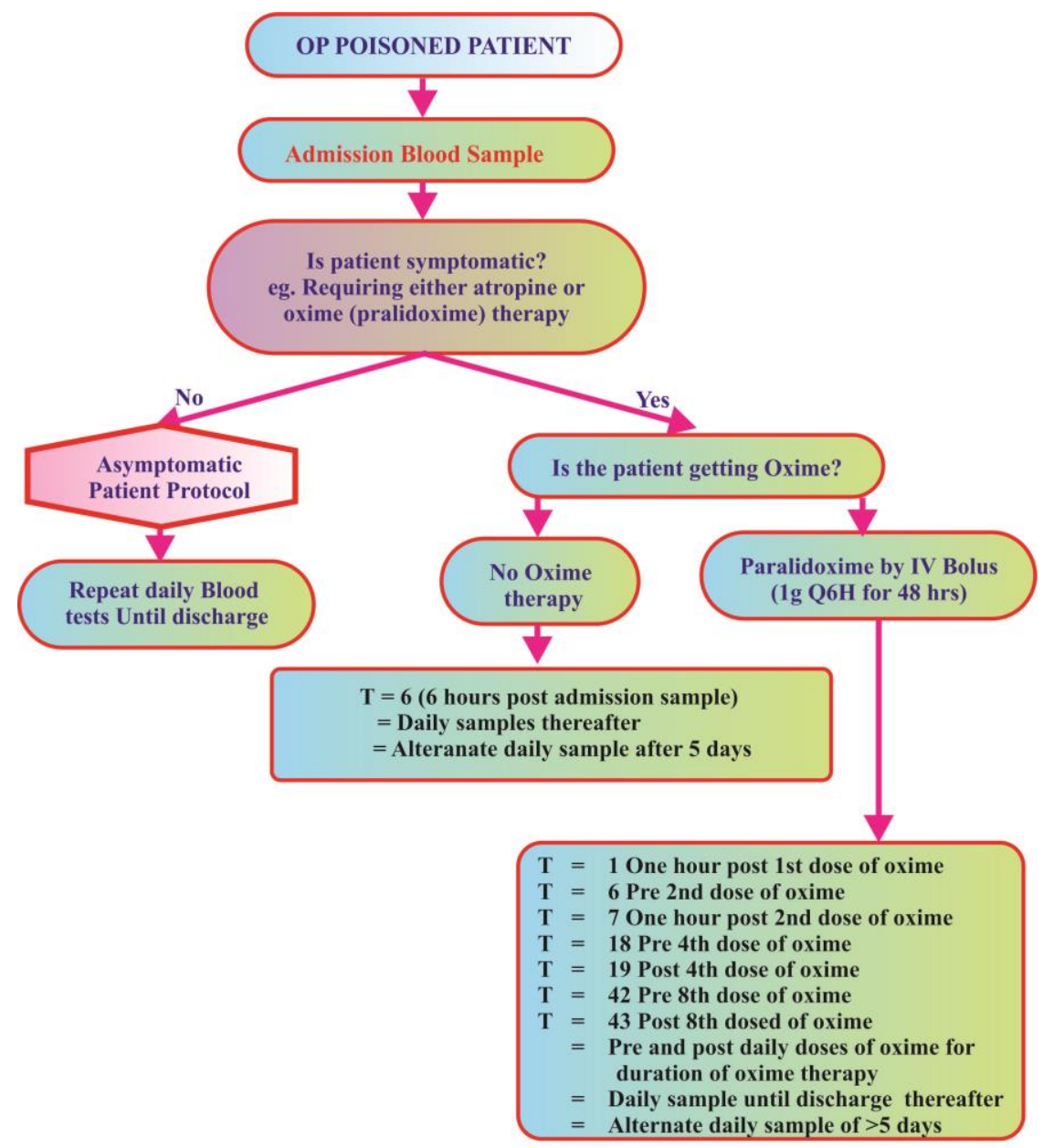

Fig. 3: Nomographic Representation of Pesticide Poisoning Management.

\section{Discussion}

Poisoning is a common medico-social problem now days all over the world. The differences between the sexes are statistically significant. The age group between20-30 was admitted to emergency department than other age groups (Eddleston 2000). The socio demographic variables are described in Table 1. There were $63.63 \%$ females and $36.36 \%$ males. This finding correlates with a study conducted in an emergency department of Mersin University Faculty of Medicine in Turkey, where the results showed that females were more vulnerable than males to poisoning. It was noted that number of poisoning decreases significantly as the age of patient increases. Suicidal poisoning (69.23\%) attempts were significantly more common than accidental poisoning $(40.90 \%)$ cases. Organophosphorus insecticide self-poisoning causes hundreds of thousands of deaths each year (Michael Eddleston $e t$ al.2005). In this study it was found that majority of poisoning cases occurred with prescription drugs and pesticides in young age group and women (Buddhi Prasad 2005, Eddleston 2000). The differences in the rate of suicide attempts may be attributed to many factors including seasonal characteristics, differences in socioeconomic level, increasing unemployment rates, and increasingly oppressive attitude towards women ( Kar et al.2010). Majority of cases were in the age group of 11-30 years and maximum cases were found between 21-30 years which can be explained by the fact that the persons of this age group are suffering from stress of the modern lifestyles, failure in love, family problems, nuclear family concept and also early marriage in the rural community along with its added familial responsibilities etc. Associated comorbid conditions like incurable disease conditions like aids, Physical and mental disorders motivate people to consume poison. The greater number of the poisoning cases in this study occurred via the oral route so sale of drugs without prescription should be discouraged (Ghimire et al.2004).

\section{Conclusion}

It was found that majority of poisoning cases occurred with pesticides, for suicidal purposes, in young age group (11-30 yrs) and women (Maharani et al.2013). The three most common agents causing poisoning were organophosphorus compounds, cow dung powder, paraquet. Based on the results of the present study, women of young age comprise the major risk group. Awareness and education about the potential toxicity of commonly used pesticides and drugs may help in reducing the burden of poisoning (Kar et al.2010). Public education against domestic violence and timely psychosocial management of the vulnerable cases through a protracted community based mental health program may help to reduce morbidity and mortality (Erhan Zohre et al.2015) We, as a developing country should handle the multifunctional tasks and provide broad toxicological information service, which can disseminate information to the public regarding poison prevention.

\section{Significance of study}

This study highlights the different types of poisoning cases and its management in a tertiary care hospital.

\section{Acknowledgement}

We are verymuch delighted to connote our vehement indebtedness to Thiru.R.Vijayakumhar, our Managing Trustee and Dr.P.Sukumaran, Dean, Sri Ramakrishna Hospital for their support.It gives me great pleasure to record my deep sense of gratitude and indebtedness 
Dr.T.K.Ravi,M.Pharm.,Ph.D.,FAGE.,Principal,College of Pharmacy, Coimbatore for his constant encouragement.

\section{References}

[1] Deepak Pokhrel et al. (2008) kathmandu university journal of science, engineering and technology vol. i, no. v, september, pp 4048.

[2] Dash SK et al. (2005) Sociodemographic Profile of Poisoning Cases. JIAFM. 27: 133-8.

[3] Batra AK et al. (2003), Poisoning: An Unnatural cause of morbidity and mortality in Rural India. JAP.51:955-960.

[4] Michael Eddleston et al. (2005), Differences between organophosphorus in human self-poisoning: a prospective cohort study.

[5] Eddleston M (2000), Pattern and problems of self-poisoning in the developing world. Q J Med, 93:715-731. http://dx.doi.org/10.1093/qjmed/93.11.715.

[6] Abubakar S et al. (2014), A Study on Pattern of Poisoning Cases in a Tertiary Care. Hospital, Bangalore Department of Pharmacy Practice, Visveswarapura Institute of Pharmaceutical SciencesIndian Journal of Pharmacy Practice Volume 7 Issue 1.

[7] Erhan Zöhre et al. (2015), Retrospective Analysis of Poisoning Cases Admitted to the Emergency Medicine, Archives of Iranian Medicine, Volume 18, Number 2.

[8] B. Maharani et al. (2013) Profile of poisoning cases in a Tertiary care Hospital, Tamil NADU India.

[9] Dr. S. M. Kar, MD et al. (2010), An Epidemiological study of Organophosphorus Poisoning at Manipal Teaching Hospital, Pokhara, Nepal.

[10] Khadka SB et al. (2005), A study of poisoning cases in emergency Kathmandu College Teaching Hospital Vol. 3, No. 4, Issue 12, 388 391.

[11] Thapa SR et al.(2008), Pattern of poisoning cases in Emergency Department of Kathmandu Medical College, Sinamangal, Nepal Vol. 6, No. 2, Issue 22, 209-213.

[12] Buddhi Prasad (2005),Paudyal Poisoning: Pattern And Profile Of Admitted Cases in a Hospital in Central Nepal.

[13] Ghimire RH et al. (2004),A comparative study of acute poisoning in Nepal at tertiary secondary level hospitals: Journal of Nepal Medical Association :43;130-133

[14] Dart RC, (2003) ed. Medical Toxicology, 3rd edn. Philadelphia: Lippincott Williams \& Wilkins.

[15] Bharati U et al. (2001), Study of Acute Poisoning in Nepal Medical College Teaching Hospital; NMCJ Vol. 2 No. 2 (83).

[16] Ghazi-Khansari(1995) A prospective study on the fatal outcomes of poisoning in Tehran. Veterinary and Human Toxicology; 37 (5):449-52.

[17] M.Eddleston. (2000) Pattern and problems of self-poisoning in the developing world. Q J Med; 93:715-731. http://dx.doi.org/10.1093/qimed/93.11.715.

[18] Kiran N,et al. (2008) Pattern of poisoning reported at south Indian tertiary care hospital. Indian Journal of Forensic Medicine Toxicology. 2(2).17-9. 